\title{
Desempenho de novilhas de corte até o parto recebendo diferentes níveis de suplementação durante o período reprodutivo, aos 14 meses de idade
}

\author{
Ricardo Zambarda Vaz ${ }^{1}$, João Restle ${ }^{2}$, Márcia Bitencourt Vaz $^{3}$, Leonir Luiz Pascoal ${ }^{4}$, Fabiano \\ Nunes Vaz ${ }^{5}$, Ivan Luiz Brondani ${ }^{4}$, Dari Celestino Alves Filho ${ }^{4}$, José Neuman Miranda Neiva ${ }^{6}$ \\ 1 Universidade Regional Integrada das Missões e Alto Uruguai - URI Santiago. \\ 2 Departamento de Zootecnia - Faculdade de Veterinária - UFG. \\ ${ }^{3}$ Acadêmica Biologia - URI Santiago. \\ ${ }^{4}$ Departamento de Zootecnia - UFSM \\ 5 Unipampa-Dom Pedrito, RS. \\ 6 UFT.
}

RESUMO - Avaliou-se o desempenho de novilhas de corte até o parto submetidas a diferentes níveis de suplementação em pastagem natural durante o primeiro período reprodutivo, dos 14 aos 17 meses. Foram utilizadas 98 novilhas contemporâneas do mesmo rebanho dos grupos genéticos Charolês, Nelore e suas cruzas, com peso médio de $255 \mathrm{~kg}$. As novilhas foram distribuídas em três grupos: sem suplementação; com suplementação de $3,5 \mathrm{~g} / \mathrm{kg}$ do peso corporal; com suplementação de $7,0 \mathrm{~g} / \mathrm{kg}$ do peso corporal. O peso ao final e o ganho de peso médio diário durante o período de suplementação foi maior entre as novilhas do grupo com suplementação na proporção de $7,0 \mathrm{~g} / \mathrm{kg}(322 \mathrm{e} 0,701 \mathrm{~kg})$ em comparação àquelas sob suplementação na proporção de $3,5 \mathrm{~g} / \mathrm{kg}(302$ e $0,464 \mathrm{~kg})$ e sem suplementação $(288$ e $0,425 \mathrm{~kg})$, que não diferiram entre si. O escore de condição corporal ao final da suplementação diferiu entre os três grupos com 3,07; 3,33 e 3,47 pontos, respectivamente, para novilhas sem suplementação; com suplementação na proporção de $3,5 \mathrm{~g} / \mathrm{kg}$ do peso corporal; com suplementação na proporção de $7,0 \mathrm{~g} / \mathrm{kg}$ do peso corporal. A porcentagem de prenhez foi influenciada significativamente pelo nível de suplementação, sendo de 35,0;34,2 e 70,0\%, respectivamente. Os dois grupos sob suplementação tiveram maior taxa de concepção na metade inicial do período reprodutivo. A média de idade das novilhas ao parto foi de 785, 778 e 761 dias, respectivamente. O ganho médio diário e a condição corporal foram semelhantes entre as novilhas dos dois grupos genéticos, porém o peso ao início e ao final do período de suplementação foi maior nas filhas de touros charoleses em relação às de touros nelores, refletindo-se nas taxas de manifestação de estro $(68,8$ vs. 38,2) e de prenhez $(60,9$ vs. 26,5). As características relacionadas ao parto das novilhas não foram influenciadas pelos níveis de suplementação durante o período reprodutivo. A suplementação durante o período de acasalamento aumenta o desempenho reprodutivo de novilhas aos 14 meses de idade.

Palavras-chave: Charolês, condição corporal, ganho médio diário, Nelore

\section{Performance of beef heifers until calving receiving different levels of supplementation during the breeding season, at 14 months of age}

\begin{abstract}
The objective was to evaluate the performance of beef heifers until calving receiving different levels of supplementation on native pasture during the first breeding season, from 14 to 17 months: no supplementation; $3.5 \mathrm{~g} / \mathrm{kg}$ of body weight; and $7.0 \mathrm{~g} / \mathrm{kg}$ of body weight. Ninety-eight Charolais, Nellore and their crosses, with average initial weight of $255 \mathrm{~kg}$, were used. Weight at the end and average daily weight gain during the supplementation period were higher for $7.0 \mathrm{~g} / \mathrm{kg}$ of supplement heifers (322 and $0.701 \mathrm{~kg}$ ) compared to those with $3.5 \mathrm{~g} / \mathrm{kg}$ of supplement (302 and $0.464 \mathrm{~kg}$ ) and heifers without supplementation (288 and $0.425 \mathrm{~kg}$ ), which did not differ from each other. Body condition score at the end of the supplementation was different between the three treatments, being 3.03, 3.33 and 3.47 points for heifers without supplementation; $3.5 \mathrm{~g} / \mathrm{kg}$ of body weight; and $7.0 \mathrm{~g} / \mathrm{kg}$ of body weight, respectively. Pregnancy rate was significantly affected by supplementation level, being 35.0, 34.2 and 70.0\%, respectively. Heifers of the two supplementation treatments had higher conception rate at the first half of the reproductive period. Average heifer ages at calving were of 785, 778 and 761 days, respectively. The average daily weight and body condition of the heifers of the two genetic groups were similar; however, the initial and final weight of the supplementation period was higher for Charolais bulls daughters, compared with Nellore bulls daughters, reflecting on the heat $(68.8$ vs. $38.2 \%)$ and pregnancy (60.9 vs. $26.5 \%)$ rates. Characteristics related to calving were not affected by the supplementation levels during the reproductive period. The supplementation during the first breeding season increases reproductive performance of heifers at 14 months of age.
\end{abstract}

Key Words: average daily gain, body condition, Charolais, Nellore

Recebido em 18/10/2010 e aprovado em 23/8/2011.

Correspondências devem ser enviadas para: rzvaz@terra.com.br 


\section{Introdução}

O sucesso competitivo da pecuária de corte frente às outras modalidades de exploração agropecuária depende da máxima eficiência na produção e do aumento da rentabilidade do sistema. Para que isso ocorra, é necessário que exista correto planejamento nutricional das diferentes categorias animais (Vaz et al., 2000).

A interferência nos sistemas de produção visando ao aumento da taxa de natalidade eleva os índices de produtividade do rebanho. Entretanto, o início da atividade reprodutiva nas fêmeas bovinas é de extrema importância e tem grande influência no desempenho do rebanho de cria (Restle et al., 1999b). Para que a manifestação da puberdade ocorra, a recria das novilhas ganha maior magnitude e deve estar relacionada aos objetivos do sistema produtivo, proporcionando a primeira concepção na idade desejada (Pilau \& Lobato, 2006).

A pecuária de corte no Sul do País caracteriza-se pela sua natureza extensiva, tendo a pastagem natural como alicerce. No entanto, a disponibilidade e principalmente a qualidade da forragem sofrem oscilações entre as estações do ano, o que resulta em diferentes respostas de desempenho animal com impactos na eficiência (Vaz \& Lobato, 2010b). Para contornar o problema de qualidade na pastagem natural e potencializar o desempenho animal, a suplementação durante o período de verão é uma alternativa, por ser uma prática de custo relativamente baixa e de fácil implantação na propriedade (Pascoal \& Restle, 1996).

Este trabalho foi realizado com o objetivo de avaliar o desenvolvimento e o desempenho reprodutivo de novilhas de corte Charolês, Nelore e suas cruzas desde o seu acasalamento aos 14 meses até o seu primeiro parto mantidas em pastagens naturais e submetidas a suplementação durante o período de acasalamento.

\section{Material e Métodos}

O experimento foi desenvolvido nas dependências do Departamento de Zootecnia da Universidade Federal de Santa Maria, localizada na região fisiográfica denominada Depressão Central do Estado do Rio Grande do Sul. A altitude é de $95 \mathrm{~m}$, latitude $29^{\circ} 43^{\prime}$ sul e longitude de $53^{\circ} 42^{\prime}$ oeste. O clima da região é $\mathrm{Cfa}$ (subtropical úmido), conforme a classificação de Köppen (Moreno, 1961).

Foram utilizadas 98 novilhas com idade média inicial de 14 meses e peso médio inicial de $255 \mathrm{~kg}$ dos grupos genéticos Charolês (CH), Nelore (NE), $1 / 2 \mathrm{CH}^{1 / 2} \mathrm{NE}, 1 / 2 \mathrm{NE} 1 / 2 \mathrm{CH}, 3 / 4 \mathrm{CH}$ $1 / 4 \mathrm{NE}, 3 / 4 \mathrm{NE} 1 / 4 \mathrm{CH}, 5 / 8 \mathrm{CH} 3 / 8 \mathrm{NE}$ e $5 / 8 \mathrm{NE} 3 / 8 \mathrm{CH}$. Os touros pais das novilhas charolesas e nelores definidas foram os mesmos pais dos animais mestiços. Na distribuição dos tratamentos às novilhas, adotou-se como critério o grupo genético, porém, para as análises estatísticas, as novilhas foram distribuídas em dois grupos: filhas de touros charoleses e filhas de touros nelores, devido ao reduzido número de fêmeas em determinados grupos genéticos.

Previamente ao experimento, as fêmeas foram mantidas em pastagem natural com suas mães até a época do desmame realizado com idade média de sete meses. Dos 7 aos 13 meses, foram mantidas em pastagem cultivada de inverno composta de triticale (Tritico secale) e azevém (Lolium multiflorum), com lotação média de 5,7 fêmeas/ha ou $1.200 \mathrm{~kg}$ de peso vivo/ha.

Durante o período de verão (dezembro a fevereiro), foram mantidas em campo nativo em lotação média de 3,0 novilhas $/$ ha ou $810 \mathrm{~kg}$ de peso corporal $/$ ha e submetidas a um dos seguintes níveis de suplementação: novilhas sem suplementação; novilhas sob suplementação com concentrado na proporção de $3,5 \mathrm{~g} / \mathrm{kg}$ de peso corporal; novilhas sob suplementação com concentrado na proporção de $7,0 \mathrm{~g} / \mathrm{kg}$ de peso corporal.

O potreiro utilizado foi adubado durante o período de inverno com introdução da cultura de aveia via semeadura direta. Após o término da cultura, foram realizados roçada e diferimento por 45 dias, com o objetivo de aumentar o conteúdo de matéria seca.

A adaptação das novilhas ao manejo de separação dos lotes e ao suplemento (Tabela 1) teve duração de 19 dias e foi realizada de forma gradativa.

A suplementação foi realizada durante 90 dias, diariamente às $7 \mathrm{~h}$, em piquetes apropriados providos de cochos com disponibilidade de área de acesso de 1,0 m linear/animal, para proporcionar desta forma oportunidade de consumo mais uniforme do suplemento. Os animais eram

Tabela 1 - Composição alimentar e química do suplemento Ingrediente Participação $(\mathrm{g} / \mathrm{kg}$ de matéria natural)

\begin{tabular}{lc}
\hline & Componentes do suplemento \\
Farelo de trigo & 770 \\
Casca de soja & 200 \\
Melaço & 30 \\
& \\
Matéria seca & \\
Proteína bruta & 918 \\
Fibra bruta & 125 \\
Extrato etéreo & 238 \\
Matéria mineral & 32,3 \\
Extrativos não-nitrogenámín & 50,4 \\
Nutrientes digestíveis totais & 414 \\
Análises realizadas no Laboratório de Nutrição Animal - EMBRAPA - Bagé.
\end{tabular}


mochos, contemporâneos, e foram sempre mantidos juntos, não ocorrendo dominância.

O lote de novilhas, independentemente do nível de suplementação, sempre foi mantido em grupo único no mesmo campo nativo provido com água corrente, tendo à disposição sal + minerais fornecidos em cochos. Durante o período de consumo do suplemento, o grupo controle (sem suplementação) permaneceu em um piquete ao lado, sem acesso à pastagem, com o intuito de uniformizar o manejo. Após o consumo de suplemento, as novilhas retornavam ao campo nativo, onde permaneciam o restante do dia.

As pesagens foram realizadas no início e ao final do período experimental, e a cada 21 dias, após jejum de oito horas, com pesagens intermediárias para monitoramento do ganho do peso e ajuste do consumo de suplemento. $\mathrm{O}$ ganho médio diário foi obtido pela diferença entre os pesos finais e iniciais das novilhas divididos pelo número de dias do período avaliado. Na pesagem final foi realizada a avaliação subjetiva do escore de condição corporal (Lowman et al., 1973), sendo avaliada visualmente, utilizando escores de 1 a 5 , em que $1=$ muito magro; $2=$ magro; $3=$ médio $; 4=$ gordo e 5 = muito gordo.

O período de suplementação acompanhou o período de acasalamento, utilizando a inseminação artificial como método reprodutivo, sem rufiões, com duas observações diárias para observação do estro: uma pela manhã e outra à tarde. As novilhas que manifestavam estro pela manhã eram inseminadas à tarde e aquelas que manifestavam estro à tarde eram inseminadas na manhã do dia seguinte. Utilizou-se sêmen de touros da raça Red Angus oriundos de touros com diferença esperada na progênie (DEP) negativa para peso ao nascimento, procurando-se evitar problemas de distocia. O desempenho reprodutivo foi avaliado 60 dias após o término do período de acasalamento, via palpação retal, quantificando-se as taxas de prenhez. As taxas de manifestação de estros e parição foram estimadas por intermédio da equação: (número de novilhas que manifestaram estro ou que pariram/número total de novilhas nos tratamentos) $* 100$.

Por ocasião da inseminação artificial, foram avaliados o peso e a idade das novilhas. Após o período de acasalamento as novilhas foram mantidas em campo nativo nos meses de março a maio. Desde junho até aproximadamente 45 dias antes do provável parto tiveram acesso, em pastejo horário de duas horas, à pastagem cultivada de aveia e azevém. No parto foram avaliados o peso e a condição corporal dos animais e dos respectivos bezerros.

As vacinações seguiram o calendário da Secretaria da Agricultura do Rio Grande do Sul e o controle de endo e ectoparasitas, foi realizado com produtos específicos, de acordo com o grau de infestação. As estimativas da massa de forragem disponível foram realizadas pelo método comparativo (Haydock \& Shaw, 1975) a cada 21 dias. Com as amostras retiradas para determinação da disponibilidade da pastagem, era feita uma amostra composta, e desta eram retiradas duas amostras para posteriores análises laboratoriais. As amostras de forragem e concentrado foram analisadas quanto ao conteúdo de nitrogênio $(\mathrm{N})$, utilizando-se o método de Kjeldahl (AOAC, 1984), com posterior multiplicação pelo fator 6,25 para obtenção do teor de PB. Também avaliou-se a digestibilidade in vitro da matéria orgânica (DIVMO) das amostras, seguindo a técnica de Tilley \& Terry (1963).

O delineamento experimental foi inteiramente casualisado, sendo os dados submetidos à análise de variância e de regressão, seguindo o modelo abaixo:

$\mathrm{Y}_{\mathrm{ijkl}}=\mu+\mathrm{NSU}_{\mathrm{i}}+\mathrm{RP}_{\mathrm{j}}+(\mathrm{NSU} * \mathrm{RP})_{\mathrm{ij}}+\beta_{1}\left(\mathrm{IN}_{\mathrm{ijk}}-\right.$ média IN $)$ $+\beta_{2}\left(\mathrm{IV}_{\mathrm{ijkl}}-\right.$ média IV $)+\beta_{3}\left(\mathrm{IV}^{2}-\right.$ média IV $\left.{ }^{2}\right)+\mathrm{E}_{\mathrm{ijkl}}$ em que: $\mathrm{Y}_{\mathrm{ijkl}}=$ variáveis dependentes; $\mu=$ constante geral; $\mathrm{NSU}_{\mathrm{i}}=$ efeito do nível de suplementação $\mathrm{i}$, sendo $\mathrm{i}=1$ (zero de suplementação); $2(3,5 \mathrm{~g} / \mathrm{kg}$ do peso corporal de suplementação) e $3(7,0 \mathrm{~g} / \mathrm{kg}$ do peso corporal de suplementação); $R_{j}=$ efeito de grupo genético $j$, sendo $j=1$ (filhas de touro Charolês) e 2 (filhas de touro Nelore); $(\mathrm{NSU} * \mathrm{RP})_{\mathrm{ij}}=$ interação do nível de suplementação i e do grupo genético $\mathrm{j} ; \beta_{1}=$ coeficiente de regressão linear na idade da novilha IN; IN = covariável idade da novilha ao início do experimento; $\beta_{2}, \beta_{3}=$ coeficientes de regressão linear e quadrático na idade da mãe da novilha IV e IV ${ }^{2}$, respectivamente; IV e IV ${ }^{2}$ idade da mãe da novilha linear e quadrático no início do experimento; $\mathrm{E}_{\mathrm{ijkl}}=$ erro aleatório assumindo $\operatorname{NID}\left(0 ; \sigma^{2}\right)$.

Para as características relacionadas ao parto das novilhas utilizou-se o seguinte modelo:

$\mathrm{Y}_{\mathrm{ijkl}}=\mu+\mathrm{NSU}_{\mathrm{i}}+\mathrm{RP}_{\mathrm{j}}+\mathrm{NSU}^{*} \mathrm{RP}_{\mathrm{ij}}+\mathrm{S}_{\mathrm{k}}+\beta_{1}\left(\mathrm{IN}_{\mathrm{ijklm}}-\right.$ média $\mathrm{IN})+\beta_{2}\left(\mathrm{IV}_{\mathrm{ijklm}}-\right.$ média IV $)+\beta_{3}\left(\mathrm{IV}^{2}-\right.$ média IV $\left.^{2}\right)+\mathrm{E}_{\mathrm{ijklm}}$ em que: $Y_{i j k l m}=$ variáveis dependentes; $\mu=$ constante geral; $\mathrm{NSU}_{\mathrm{i}}=$ efeito do nível de suplementação $\mathrm{i}$, sendo $\mathrm{i}=1$ (zero de suplementação); $2(3,5 \mathrm{~g} / \mathrm{kg}$ do peso corporal de suplementação) e $3(7,0 \mathrm{~g} / \mathrm{kg}$ do peso corporal de suplementação); $R P_{j}=$ efeito de grupo genético $j$, sendo $j=1$ (filhas de touro charolês) e 2 (filhas de touro nelore); $(\mathrm{NSU} * \mathrm{RP})_{\mathrm{ij}}=$ interação do nível de suplementação i e do grupo genético $j ; S_{k}=$ efeito do sexo do bezerro $\mathrm{k} ; \beta_{1}=$ coeficiente de regressão linear na idade da novilha IN; IN = covariável idade da novilha ao início do experimento; $\beta_{2}, \beta_{3}=$ coeficientes de regressão linear e quadrático na idade da mãe da novilha IV e IV ${ }^{2}$, respectivamente; IV e IV ${ }^{2}$ idade da mãe da novilha linear e quadrático no início do experimento; $\mathrm{E}_{\mathrm{ijkl}}=$ erro aleatório assumindo $\operatorname{NID}\left(0 ; \sigma^{2}\right)$. Os 
dados foram submetidos a análise de variância, ao teste $\mathrm{F}$ e quando o mesmo foi significativo $(\mathrm{P}<0,05)$, as médias foram comparadas pelo teste Tukey no mesmo nível de significância do teste $\mathrm{F}$.

Para avaliar as taxas de manifestação de estro, prenhez, parição e distribuição dos estros dentro do período de acasalamento, foi utilizado o teste do qui-quadrado $(\mathrm{P}<0,05)$.

\section{Resultados e Discussão}

Não houve interação significativa para as variáveis estudadas entre níveis de suplementação e grupo genético $(\mathrm{P}>0,05)$, desta forma, os resultados são apresentados e discutidos separadamente para esses efeitos.

Durante o período de suplementação os valores observados de matéria seca foram de 2.463,2.033 e $1.890 \mathrm{~kg}$ de matéria seca/ha nos meses de dezembro, janeiro e fevereiro, respectivamente, correspondentes ao período de suplementação. Estes valores não interferiram no desempenho animal, pois as condições climáticas foram propícias ao crescimento das pastagens naturais, com altas temperaturas e precipitações acima das normalmente registradas.

O fornecimento de suplementos aos animais geralmente transforma-se em ganho de peso aditivo, pois animais mantidos exclusivamente em pastagem nativa, embora com boa oferta forrageira, a qualidade da mesma pode ser limitante, pela baixa digestibilidade do material ingerido pelos animais (Van Soest, 1994).

As análises da pastagem natural mostram declínio na qualidade no decorrer do verão e a proximidade do outono, com o amadurecimento das espécies forrageiras $(7,7 ; 6,5$ e $6,6 \mathrm{~g} / 100 \mathrm{~g}$ na matéria natural de proteína bruta, respectivamente, para dezembro, janeiro e fevereiro), fator determinante no desempenho, associado à menor digestibilidade da matéria orgânica $(42,6 ; 32,8$ e 32,5 g/100 g na matéria natural de DIVMO, respectivamente, para dezembro, janeiro e fevereiro) no processo de ruminação, enchimento do rúmen, taxa de passagem e ao consumo de alimentos, fator mais relevante para a produção que sua digestibilidade.
Os animais submetidos ao nível de suplementação de $7,0 \mathrm{~g} / \mathrm{kg}$ de peso corporal apresentaram maior ganho de peso médio diário $(\mathrm{P}<0,05)$ em comparação àqueles submetidos a 3,5 g/kg de suplementação e aqueles mantidos exclusivamente em campo nativo, os quais não diferiram entre si (Tabela 2). O maior ganho de peso das novilhas do nível de suplementação de $7,0 \mathrm{~g} / \mathrm{kg}$ de peso corporal é reflexo do maior aporte de proteína e energia via suplemento concentrado $(12,5 \mathrm{~g} / 100 \mathrm{~g}$ de proteína bruta e $67,3 \mathrm{~g} / 100 \mathrm{~g}$ de nutrientes digestíveis totais na matéria natural), quando comparados ao aporte da pastagem natural $(7,0 \mathrm{~g} / 100 \mathrm{~g}$ de proteína bruta e 35,96 g/100 g de DIVMO).

As exigências nutricionais das fêmeas em estudo para ganhos de $0,800 \mathrm{~kg}$ peso corporal/dia são de $6,25 \mathrm{~kg}$ de matéria seca, $0,740 \mathrm{~g}$ de proteína bruta e $4,67 \mathrm{~kg}$ de nutrientes digestíveis totais (NRC,1996). De acordo com os dados, no nível de $3,5 \mathrm{~g} / \mathrm{kg}$ de suplementação, o suplemento forneceu $18,5 \%$ da proteína bruta e $15,8 \%$ dos nutrientes digestíveis totais exigidos por novilhas de corte para ganho de $0,8 \mathrm{~kg} / \mathrm{dia}$. Já com a suplementação de $7,0 \mathrm{~g} / \mathrm{kg}$, o suplemento forneceu 38,4 e $32,8 \%$ da exigência de proteína bruta e nutrientes digestíveis totais/animal/dia, respectivamente.

A oferta de suplemento na proporção de $3,5 \mathrm{~g} / \mathrm{kg}$ não foi suficiente para promover aumento significativo no ganho de peso dos animais, quando comparados aos mantidos exclusivamente em pastagem natural. Este fato se deve à semelhança entre o concentrado fornecido e o pasto nativo quando selecionado para o consumo animal. Desse modo, nas novilhas do grupo sob suplementação com $3,5 \mathrm{~g} / \mathrm{kg}$ de suplemento, provavelmente houve apenas efeito substitutivo, com pouca agregação do suplemento no ganho de peso das novilhas. O ganho de peso das novilhas mantidas exclusivamente em pastagem natural, de $0,425 \mathrm{~kg} / \mathrm{dia}$, foi obtido pela seletividade dos animais no momento da apreensão dos alimentos, proporcionado pelas ofertas de matéria seca. A qualidade do material ingerido pelo animal é semelhante àquele ofertado em situações de escassez forrageira. Ao trabalhar com boas ofertas forrageiras, o consumido pelo animal é superior ao

Tabela 2 - Desenvolvimento de novilhas nos níveis de suplementação

\begin{tabular}{|c|c|c|c|c|c|}
\hline \multirow[t]{2}{*}{ Características } & \multicolumn{3}{|c|}{ Níveis de suplementação } & \multirow[t]{2}{*}{$\operatorname{Pr}>\mathrm{F}$} & \multirow[t]{2}{*}{$\mathrm{CV}(\%)$} \\
\hline & Sem suplementação & $3,5 \mathrm{~g} / \mathrm{kg}$ do peso corporal & $7,0 \mathrm{~g} / \mathrm{kg}$ do peso corporal & & \\
\hline Consumo médio diário ( $\mathrm{kg}$ de $\mathrm{MS}$ ) & 0,00 & 1,10 & 2,27 & & \\
\hline Peso início do acasalamento, $\mathrm{kg}$ & $251 \mathrm{a}$ & $259 a$ & $258 \mathrm{a}$ & 0,6457 & 12,05 \\
\hline Peso final do acasalamento, $\mathrm{kg}$ & $288 \mathrm{~b}$ & $302 b$ & $322 \mathrm{a}$ & 0,0050 & 11,67 \\
\hline Ganho médio diário, $\mathrm{kg}$ & $0,425 b$ & $0,470 \mathrm{~b}$ & $0,701 \mathrm{a}$ & 0,0001 & 38,90 \\
\hline Condição corporal final \# & $3,03 b$ & $3,33 \mathrm{a}$ & $3,47 \mathrm{a}$ & 0,0001 & 8,16 \\
\hline
\end{tabular}

a,b Médias na mesma linha seguidas por letras minúsculas diferentes diferem entre si $(\mathrm{P}<0,05)$ pelo teste de Tukey.

\# 1 - muito magra; 2 - magra; 3 - média; 4 - gorda; 5 - muito gorda.

$\mathrm{CV}$ - coeficiente de variação. 
ofertado (Gonçalves et al., 2009), com valores da simulação de pastejo condizentes com ganhos realizados pelos animais (Pilau \& Lobato, 2006).

Os animais sob suplementação no nível de $3,5 \mathrm{~g} / \mathrm{kg}$ tiveram aumento de $9,1 \%$ no ganho de peso sobre os animais criados em campo nativo, no entanto, nos animais sob suplementação no nível de $7,0 \mathrm{~g} / \mathrm{kg}$, o incremento foi de $65 \%$ ( 0,701 vs. $0,425 \mathrm{~kg} / \mathrm{dia})$. Isso comprova que houve efeito aditivo quando se mudou o nível de suplementação de 3,5 para $7,0 \mathrm{~g} / \mathrm{kg}$ do peso corporal. O efeito aditivo no ganho de peso com o aumento da suplementação deve ter sido motivado por fatores como maior consumo de matéria seca, melhor balanceamento dos nutrientes da dieta e maior seletividade da pastagem natural. As relações de qualidade e quantidade das forragens e o desempenho animal são alterados pelo uso de suplementos conforme os efeitos de substituição ou adição (Pilau \& Lobato, 2006), alterado pelo nível de suplementação (Lana \& Gomes Junior, 2002).

Os maiores ganhos verificados neste estudo associados ao aumento da suplementação são provavelmente devidos ao efeito aditivo no consumo de matéria seca, aumentando a digestibilidade do alimento total consumido. Freitas et al. (2005) trabalharam com níveis de suplementação em pastagem cultivada de aveia e azevém e não observaram aumentos no ganho de peso de novilhas, devido à qualidade da forragem ofertada, não mostrando efeito aditivo no ganho de peso, e sim ganhos substitutivos comprovados pelo aumento de carga animal.

À medida que aumentou o nível de suplementação,o escore de condição corporal final melhorou (Tabela 2) e esse aumento foi significativo entre os três níveis de suplementação. Mesmo não havendo diferença significativa no ganho de peso médio diário das fêmeas do grupo que recebeu suplemento na proporção de $3,5 \mathrm{~g} / \mathrm{kg}$ em relação às mantidas exclusivamente em campo nativo, estas atingiram melhor condição corporal ao final do período de suplementação, devido ao maior aporte de energia via suplemento. Em novilhas, o aumento das reservas corporais pode ter reflexos no desempenho reprodutivo e na futura gestação e lactação.

$\mathrm{O}$ acúmulo de gordura corporal está associado à composição do ganho de peso e se relaciona com o nível energético da alimentação. Animais em pastagens com elevado teor de proteína bruta associadas à suplementação energética tendem a depositar gordura corporal precocemente e em maior quantidade em relação àqueles exclusivamente em pastejo (Frizzo et al., 2003; Pilau et al., 2004), assim, a condição corporal dos animais é altamente dependente da relação de proteína e energia nos nutrientes consumidos (Poppi \& McLennan, 1995). Restle et al. (2000) verificaram relação linear entre o nível de suplementação energética e o escore de condição corporal, sem alteração no ganho de peso, e atribuíram o fato ao maior aporte energético aos animais sob suplementação, alterando a composição do ganho de peso, com maior deposição de gordura nas vacas com maior nível de suplementação.

O desenvolvimento durante a recria é muito importante no desempenho da novilha de corte e pode determinar a idade ao primeiro acasalamento das novilhas (Pilau et al., 2004; Freitas et al., 2005). Segundo Rovira (1996), para acasalamento dos 14 aos 16 meses, a fêmea deve ter alcançado desenvolvimento em torno de $65 \%$ do seu peso adulto. Essa situação é difícil de ser conseguida em rebanhos heterogêneos, ao passo que, em rebanhos homogêneos, a própria variação de idade tem determinado a puberdade das novilhas em idades desuniformes.

Nos rebanhos dos sistemas pecuários, verificam-se indivíduos com genética para respostas satisfatórias para reprodução com o primeiro acasalamento aos 14, 24 e 36 meses e outros animais que nem aos 36 meses possuem condições de acasalamento, sendo descartados do sistema de produção (Fries, 2004; Lobato \& Vaz, 2006); outros com avanço genético obtido por seleção e descarte de animais (Deese \& Koger, 1967); ou ainda com manejos de alimentação diferenciados para privilegiar determinada categoria corrigindo diferenças durante a recria, permitindo maior número de novilhas com melhor desenvolvimento a idades mais jovens (Pereira Neto et al., 1999).

Os pesos no início e no fim do período reprodutivo são características importantes por se correlacionarem à manifestação de estros e à prenhez de novilhas. A correlação entre peso final e essas duas variáveis apresentou coeficientes de 0,58 e $0,48(\mathrm{P}<0,0001)$, respectivamente. Restle et al. (1999b) também observaram maiores percentuais de estro e prenhez aos 28 meses com aumentos de peso das novilhas.

O peso no início do período reprodutivo é reflexo do desenvolvimento prévio das fêmeas. A correlação entre esta variável e as porcentagens de estro e de prenhez mostrou coeficientes de 0,60 e $0,49(\mathrm{P}<0,01)$, respectivamente. O desenvolvimento pré-desmame (Restle et al., 1999b), assim como o crescimento pós-desmame (Wiltbank et al., 1985), tem influência no desempenho reprodutivo de novilhas.

As novilhas que receberam suplemento na proporção de $7,0 \mathrm{~g} / \mathrm{kg}$ de peso corporal apresentaram maiores taxas de estro, prenhez e parição se comparadas àquelas que receberam suplemento na proporção de $3,5 \mathrm{~g} / \mathrm{kg}$ de peso corporal e àquelas sem suplementação (Tabela 3). Apesar de terem recebido alimentação suplementar, as fêmeas do grupo sob suplementação no nível de $3,5 \mathrm{~g} / \mathrm{kg}$ não apresentaram maior porcentagem de estro $(\mathrm{P}>0,05)$ em 
comparação às sem suplementação e isso comprova a necessidade de melhores níveis de alimentação.

Comparando os animais dos três grupos, verificou-se aumento de $100 \%$ na taxa de prenhez, comprovando que o nível de nutrição das novilhas é o responsável por bons desempenhos reprodutivos. Short \& Bellows (1971) observaram aumento de 42,2\% dos níveis alto e médio em relação ao nível mais baixo de nutrição, mas não notaram diferença entre estes, cujos valores foram de 90,0; 90,0 e $63,3 \%$, respectivamente.

A manifestação de estro foi reflexo do ganho de peso e do escore de condição corporal ao final do período reprodutivo apresentado pelas novilhas em cada nível de suplementação (Tabelas 2 e 3). A porcentagem de estros foi maior nas fêmeas com melhores condições corporais, e o coeficiente de correlação destas variáveis foi de 0,38 $(\mathrm{P}<0,01)$. A reprodução em bovinos de corte está relacionada ao ganho de peso e ao estado corporal das fêmeas. Novilhas prenhes ao final do primeiro período reprodutivo são as mais pesadas e as de melhor condição corporal (Restle et al., 1999b; Semmelmann et al., 2001; Rocha \& Lobato, 2002; Vaz \& Lobato 2010a).

Os pesos na primeira inseminação foram similares nos três grupos (Tabela 3), e isso comprova que, para ciclar, a novilha necessita de determinado desenvolvimento, independentemente do nível nutricional ao qual está submetida. Hall et al. (1994) trabalharam com ganhos de 0,770 e $0,510 \mathrm{~kg} /$ dia e não observaram diferença no peso à puberdade (336 e $330 \mathrm{~kg}$, respectivamente).

O aumento do nível alimentar proporciona maior peso à puberdade (Short \& Bellows, 1971). Neste experimento, a semelhança de peso à inseminação pode ser explicada pela época de submissão aos manejos alimentares e pelo curto período de tempo de aplicação dos mesmos.

A idade da manifestação do primeiro estro, avaliada dentro do período reprodutivo não foi influenciada pelo nível de suplementação das novilhas (Tabela 4). Short \& Bellows (1971) e Wiltbank et al. (1985) demonstraram que o nível alimentar é de extrema importância no aparecimento do primeiro estro e está inversamente relacionado à idade da manifestação. Os resultados deste trabalho não mostraram a mesma tendência, talvez pelo curto período de suplementação e pela distribuição inicial de peso ao início dos tratamentos, fato pelo qual algumas novilhas em todos os tratamentos ao início do período provavelmente já possuíam condições de peso corporal para ciclarem.

A correlação entre a idade e o peso à inseminação $(0,56$; $\mathrm{P}<0,01)$ indica que as novilhas mais tardias são mais pesadas à inseminação. O coeficiente de correlação encontrado é muito similar ao verificado por Arije \& Wiltbank (1971), de 0,57 , a correlacionarem idade e peso à puberdade, e inferior ao relatado Restle et al. (1999b), de 0,70. Rocha \& Lobato (2002) observaram coeficiente de $0,17(\mathrm{P}<0,05)$ para peso e idade ao primeiro estro no período reprodutivo.

Em sistemas de reprodução precoce, é de extrema importância a prenhez no início do período reprodutivo, pois, após o parto, além das exigências de manutenção, lactação e subsequente reprodução, como ocorre com vacas adultas, as novilhas estão ainda em crescimento. Quanto mais cedo a novilha entrar em estro e ficar prenhe, maior o intervalo de recuperação no pós-parto para voltar a ciclar novamente, pois a fertilidade dos estros cresce linearmente até o terceiro estro (Byerley et al., 1987).

Nos grupos sob suplementação, a concentração de estros das novilhas se deu na primeira metade do período reprodutivo, 66,7 e 64,5\%, nos níveis 3,5 e 7,0 g de suplemento/kg de peso corporal, respectivamente, valores superiores ao de $50 \%$ das novilhas mantidas exclusivamente em pastagem natural (Tabela 4). Vaz et al. (2010) trabalharam com diferentes idades de desmame das novilhas $(\mathrm{P}>0,05) \mathrm{e}$ observaram maiores concentrações de manifestações de estro nos períodos iniciais e intermediários do período reprodutivo das novilhas, repetindo-se estas concentrações também no segundo período reprodutivo, concordando com Osoro (1986), comprovando que as novilhas que concebem no início do período reprodutivo e parem no início do período de parição apresentam maior taxa de prenhez quando primíparas.

Tabela 3 - Desempenho reprodutivo de novilhas submetidas a diferentes níveis de suplementação durante o período de acasalamento aos 14 meses de idade

\begin{tabular}{lcccc}
\hline Características & \multicolumn{3}{c}{ Níveis de suplementação } & \multicolumn{2}{c}{ CV $(\%)$} \\
\cline { 2 - 4 } & Sem suplementação & $3,5 \mathrm{~g} / \mathrm{kg}$ do peso corporal & $7,0 \mathrm{~g} / \mathrm{kg}$ do peso corporal \\
\hline Taxa de manifestação de estro, \% & $40,0 \mathrm{~B}$ & $47,4 \mathrm{~B}$ & $77,5 \mathrm{~A}$ & \\
Taxa de prenhez, \% & $35,0 \mathrm{~B}$ & $34,2 \mathrm{~B}$ & $70,0 \mathrm{~A}$ & \\
Taxa de parição, \% & $35,0 \mathrm{~B}$ & $26,3 \mathrm{~B}$ & $37,5 \mathrm{~A}$ & \\
Peso à inseminação, kg & $299,2 \mathrm{a}$ & $318,1 \mathrm{a}$ & $301,7 \mathrm{a}$ & 0,3493 \\
Idade à inseminação, dias & $472 \mathrm{a}$ & $470 \mathrm{a}$ & 10,34 \\
\hline
\end{tabular}

A,B na mesma linha diferem a 5\% pelo teste do Qui-quadrado.

a,b Médias na mesma linha seguidas por letras minúsculas diferentes diferem entre si $(\mathrm{P}<0,05)$ pelo teste Tukey.

CV - coeficiente de variação. 
Tabela 4 - Distribuição de estros no período reprodutivo e idade ao parto de novilhas

\begin{tabular}{|c|c|c|c|c|c|c|c|}
\hline \multicolumn{2}{|l|}{ Níveis de suplementação } & \multicolumn{4}{|c|}{ Período reprodutivo } & \multirow{2}{*}{\multicolumn{2}{|c|}{ Idade da vaca ao parto, dias }} \\
\hline & & \multicolumn{2}{|c|}{0 aos 45 dias } & \multicolumn{2}{|c|}{45 aos 90 dias } & & \\
\hline & $\mathrm{N}$ & $\mathrm{N}$ & $\%$ & $\mathrm{~N}$ & $\%$ & $\mathrm{~N}$ & Dias \\
\hline $3,5 \mathrm{~g} / \mathrm{kg}$ de peso corporal & 38 & 12 & $66,7 \mathrm{a}$ & 6 & $33,3 \mathrm{a}$ & 14 & 778 \\
\hline $7,0 \mathrm{~g} / \mathrm{kg}$ de peso corporal & 40 & 20 & $64,5 \mathrm{a}$ & 11 & $35,5 \mathrm{a}$ & 28 & 761 \\
\hline
\end{tabular}

\# a,b na mesma coluna diferem a $5 \%$ pelo teste do qui-quadrado. $\mathrm{P}>0,05$.

Rocha \& Lobato (2002) concluíram que o peso à desmama da bezerra é um bom indicador a ser usado junto com estratégias de nutrição para maior número de novilhas consiga conceber ao início da reprodução e, na temporada de monta subsequente, mesmo lactando, favorecer a obtenção de maior taxa de prenhez.

Os níveis de suplementação não influenciaram a idade ao parto das novilhas $(\mathrm{P}>0,05)$, cuja média foi de 775 dias, e superior ao citado por Rocha \& Lobato (2002), de 741,6 dias com fêmeas Hereford e cruzas Nelore parindo aos 24 meses de idade. Essa diferença de 33,4 dias se deve ao fato de as novilhas terem manifestado estro 35 dias mais jovens que as deste estudo. As novilhas sob suplementação no nível de 7,0 g/kg pariram 24 dias antes daquelas sem suplementação e 17 dias antes daquelas que receberam suplemento na proporção de $3,5 \mathrm{~g} / \mathrm{kg}$. Tiffin (1978), em pesquisa com diferentes níveis de alimentação no desenvolvimento e acasalamento de novilhas aos 14 meses, observou precocidade nas datas de parto para o nível alto em relação ao médio e baixo ( 9 e 36 dias, respectivamente).

Os maiores pesos verificados no início e ao fim do período de suplementação para os animais charoleses quando comparados aos nelores (Tabela 5) podem ser explicados pelo maior porte do grupo Charolês e pelo período imediatamente anterior a este estudo (inverno/ primavera), no qual os animais charoleses são mais adaptados às temperaturas adversas do inverno para a produção animal, respondendo melhor à alimentação utilizada e propiciando condições de expressar seu potencial para ganho de peso, enquanto animais nelores são adaptados a regiões tropicais e com menor seleção para ganho de peso médio diário (Pereira et al., 2000).

Para condições em que ocorrem variações climáticas com quatro estações do ano definidas, limitando a produção e qualidade das pastagens naturais, que são a base da alimentação dos animais, o cruzamento de raças é alternativa para melhorar o desempenho animal (Restle et al., 1999a; Pereira et al., 2000) e para o aproveitamento da heterose direta e materna resultante dos cruzamentos (Gregory \& Cundiff, 1980).

Existe correlação positiva entre exigências e desempenho animal, possibilitando a animais de grande porte e ou selecionados para ganho de peso, quando bem alimentados, demonstrar desempenho superior ao de genótipos de médio e pequeno porte (Ferrel \& Jenkins, 1985). Restle et al. (1999b) avaliaram o desenvolvimento de novilhas puras dos grupos Charolês e Nelore e suas cruzas F1 e observaram que as primeiras foram mais pesadas do nascimento até os 24 meses de idade, com a maior diferença de peso com $30 \%$ de superioridade aos 12 meses de idade. Os autores atribuíram este resultado à seleção intensa para ganho de peso da raça Charolesa durante o processo de sua

Tabela 5 - Médias ajustadas e erros-padrão para características de desenvolvimento e desempenho reprodutivo de novilhas de acordo com o grupo genético

\begin{tabular}{|c|c|c|c|c|}
\hline \multirow[t]{2}{*}{ Características } & \multicolumn{2}{|c|}{ Grupos genéticos } & \multirow[t]{2}{*}{$\operatorname{Pr}>F$} & \multirow[t]{2}{*}{ CV (\%) } \\
\hline & Charolês & Nelore & & \\
\hline Peso inicial do acasalamento, $\mathrm{kg}$ & $273,3 \mathrm{a}$ & $239,1 \mathrm{~b}$ & 0,0001 & 12,06 \\
\hline Peso final do acasalamento, $\mathrm{kg}$ & $319,2 \mathrm{a}$ & $288,6 b$ & 0,0003 & 11,67 \\
\hline Ganho médio diário, $\mathrm{kg}$ & $0,510 \mathrm{a}$ & $0,550 \mathrm{a}$ & 0,3567 & 38,90 \\
\hline Condição corporal \# & $3,26 \mathrm{a}$ & $3,29 \mathrm{a}$ & 0,7031 & 8,17 \\
\hline Taxa de manifestação de estros, \% & $68,8 \mathrm{~A}$ & $38,2 \mathrm{~B}$ & & \\
\hline Taxa de prenhez, \% & $60,9 \mathrm{~A}$ & $26,5 \mathrm{~B}$ & & \\
\hline Taxa de parição, \% & $58,5 \mathrm{~A}$ & $24,5 \mathrm{~B}$ & & \\
\hline Peso a inseminação, $\mathrm{kg}$ & $306,2 \mathrm{a}$ & $306,6 \mathrm{a}$ & 0,9621 & 10,34 \\
\hline Idade a inseminação, dias & $459,9 \mathrm{a}$ & $476,6 b$ & 0,0240 & 5,35 \\
\hline
\end{tabular}

a,b Médias na mesma linha seguidas por letras minúsculas diferentes diferem entre si $(\mathrm{P}<0,05)$ pelo teste Tukey.

A,B na mesma linha diferem $(\mathrm{P}>0,05)$ pelo teste do qui-quadrado.

\# 1 - muito magra; 2 - magra; 3 - media; 4 - gorda; 5 - muito gorda.

$\mathrm{CV}$ - coeficiente de variação. 
formação. Menores desenvolvimentos aos 12 meses de idade para animais nelores em relação aos charoleses e suas cruzas são relatados na literatura (Pereira et al., 2000; Cerdótes et al., 2004). Em estudos de Restle et al. (1999b) e Cerdótes et al. (2004), o melhor desempenho dos animais charoleses se manifestou em avaliações após um período de alimentação de maior qualidade quando os animais foram mantidos em pastagem cultivada de inverno/primavera, ou em confinamento (Pereira et al., 2000).

Restle et al. (1999a) demonstraram superioridade de animais charoleses em comparação a nelores no Sul do País em estudo no qual avaliaram novilhos desde o nascimento até o abate, aos 2 anos de idade, desmamados precoce e em idade convencional. Durante os dois invernos, os animais charoleses foram superiores aos nelores em ganhos de peso ( 74,84 e $36,50 \%$, respectivamente); e, durante o período de verão, quando permaneceram em campo nativo, os dois grupos tiveram desempenhos semelhantes $(0,433$ vs. $0,429 \mathrm{~kg}$, respectivamente). No estudo de Restle et al. (1999a), animais charoleses foram $35,74 \%$ mais eficientes que os nelores em ganhos de pesos dos 3 até os 24 meses de idade (349 e $257 \mathrm{~kg}$, respectivamente).

O ganho médio diário durante o período de suplementação foi muito similar (Tabela $5 ; \mathrm{P}>0,05$ ) entre os grupos genéticos Charolês e Nelore $(0,510$ vs. $0,550 \mathrm{~kg} / \mathrm{dia}$, respectivamente). Embora animais charoleses tenham sido selecionados para maior ganho de peso, este fato não se manifestou neste estudo. Isto se explica, em parte, pela adaptação dos animais nelores às elevadas temperaturas no período avaliado. Em temperaturas elevadas e limitações nutricionais, animais charoleses têm piores desempenhos se comparados aos nelores. Pereira et al. (2000) estudaram o desempenho de animais definidos e as duas gerações do cruzamento alternado das raças Charolesa e Nelore e verificaram que os animais definidos foram mais sensíveis à variação de meio ambiente, pois responderam de acordo com sua adaptação. Esses autores verificaram maiores ganhos de pesos nos animais nelores quando comparados aos charoleses no período dos 12 aos 20 meses de idade em pastagem natural $(0,168$ vs. $0,055 \mathrm{~kg} /$ dia, respectivamente), período imediatamente após manutenção em confinamento, quando animais charoleses foram superiores aos nelores em desempenho $(0,848$ vs. $0,586 \mathrm{~kg} / \mathrm{dia}$, respectivamente).

Mesmo que a seleção de animais para ganhos de peso dentro das raças, ou mesmo as partes aditivas dos cruzamentos entre raças sejam bem equacionadas e produzam genótipos adequados, o maior potencial de produção desencadeado por esta seleção ou heterose provocará aumento no consumo de alimentos, pois maior ganho de peso e maior produção de leite das vacas dependem da disponibilidade forrageira, mesmo que o animal mestiço faça um pastoreio menos seletivo ou no mínimo melhor aproveitamento do pasto (Fries, 1996).

$\mathrm{O}$ escore de condição corporal ao final do período de suplementação foi similar (Tabela $6 ; \mathrm{P}>0,05$ ) entre os grupos Charolês e Nelore, de 3,26 e 3,29 pontos, respectivamente, refletindo o ganho de peso corporal dos mesmos. Este fato é lógico, uma vez que a avaliação subjetiva do escore de condição corporal reflete a deposição de músculos e de gordura no corpo do animal. Menores valores de condição corporal para animais nelores foram relatados por Cerdótes et al. (2004) em comparação a animais charoleses (2,49 vs 2,98 pontos, respectivamente), porém esta avaliação foi após o final do período de inverno, no qual os animais nelores tiveram menor ganho de peso médio diário $(0,300 \mathrm{vs}$. $0,460 \mathrm{~kg} /$ dia, respectivamente)

Gregory et al. (1991) trabalharam com animais charoleses em boas condições de alimentação e citaram a idade à puberdade de 369 dias, inferior à relatada por Restle et al. (1999b), de 626 dias, porém em condições mais limitantes de alimentação, comprovando que o meio ambiente é fator determinante na idade à puberdade, pois nos dois estudos, o peso foi similar. Essa constatação comprova que, para manifestar a puberdade, é fundamental que a fêmea atinja determinado grau de desenvolvimento e que idade à puberdade é principalmente uma consequência da velocidade de ganho de peso, que, por sua vez, está condicionada ao meio ambiente. Este fato pode ser comprovado pelos pesos à inseminação, que foram similares nos dois grupos genéticos: 306,2 e 306,6 kg para Charolês e Nelore, respectivamente.

O maior desenvolvimento proporcionou melhores desempenhos reprodutivos, com maiores taxas de manifestação de estro durante o período reprodutivo, taxas de prenhez e de parição dos animais charoleses em comparação aos nelores, com 80,1; 129,8 e 138,8\% de superioridade, respectivamente (Tabela 5), indicando a superioridade reprodutiva de animais charoleses comparados aos nelores no Sul do País. Os dados sugerem que animais nelores mais susceptíveis a perdas reprodutivas desde a não-concepção nos estros, na manutenção de prenhez na natalidade de bezerros.

Novilhas charolesas foram mais precoces $(\mathrm{P}<0,05)$ na idade à inseminação (459,9 dias) em comparação às nelores (476,6 dias). Isto se deve, em parte, ao maior desenvolvimento anterior ao período reprodutivo. Restle et al. (1999b), em pesquisa com novilhas charolesas e nelores, também notaram maior precocidade das novilhas charolesas com valores superiores ao deste estudo, com valores de $623 \mathrm{e}$ 
Tabela 6 - Médias ajustadas e erros-padrão para características ao parto de novilhas de acordo com o nível de suplementação, sexo do bezerro e grupo genético

\begin{tabular}{|c|c|c|c|c|}
\hline & Peso ao parto (kg) & Condição corporal (pontos) & Período de gestação (dias) & Peso bezerro $(\mathrm{kg})$ \\
\hline \multicolumn{5}{|l|}{ Nível de suplementação } \\
\hline Sem suplementação & $294,8 \pm 13,2$ & $2,37 \pm 0,17$ & $284,4 \pm 2,4$ & $28,4 \pm 2,2$ \\
\hline $3,5 \mathrm{~g} / \mathrm{kg}$ de peso corporal & $303,9 \pm 7,1$ & $2,42 \pm 0,09$ & $282,6 \pm 1,3$ & $28,3 \pm 1,9$ \\
\hline Média & 303,6 & 2,4 & 282,3 & 28,3 \\
\hline $\operatorname{Pr}>F$ & 0,5502 & 0,9646 & 0,2858 & 0,9941 \\
\hline Fêmea & $300,8 \pm 8,6$ & $2,35 \pm 0,11$ & $284,6 \pm 1,6$ & $28,1 \pm 1,4$ \\
\hline $\operatorname{Pr}>\mathrm{F}$ & 0,5862 & 0,3986 & 0,0622 & 0,7678 \\
\hline \multicolumn{5}{|c|}{ Grupo genético da mãe do bezerro } \\
\hline Charolês & $310,6 \pm 6,1$ & $2,37 \pm 0,08$ & $280,1 \pm 1,1$ & $27,7 \pm 1,0$ \\
\hline Nelore & $296,5 \pm 12,7$ & $2,42 \pm 0,16$ & $284,6 \pm 2,3$ & $28,9 \pm 2,1$ \\
\hline $\operatorname{Pr}>F$ & 0,3180 & 0,8019 & 0,0787 & 0,5865 \\
\hline
\end{tabular}

$\mathrm{P}>0,05 ; \mathrm{CV}$ - coeficiente de variação.

754 dias para animais charoleses e nelores, respectivamente, porém em condições de alimentação inferior.

As variáveis relacionadas ao parto das novilhas não foram influenciadas $(\mathrm{P}>0,05)$ pelos níveis de suplementação durante o período reprodutivo (Tabela 6), uma vez que, entre os três níveis de suplementação, os pesos e as condições corporais ao parto, o período de gestação e os pesos de bezerros foram semelhantes.

As novilhas apresentavam no final do período reprodutivo peso médio de $305 \mathrm{~kg}$ (Tabela 2) e peso médio ao parto de $304 \mathrm{~kg}$. Este peso é baixo se considerado que as fêmeas estavam no início da lactação e ainda na fase de desenvolvimento. Rovira (1996) recomenda que, em acasalamentos precoces aos 14 meses de idade, a fêmeas tenha seu primeiro parto com cerca de $85 \%$ do seu peso à idade adulta para que não tenha reflexos negativos no seu desempenho reprodutivo subsequente.

Valores de ganho de peso de $81 \mathrm{~kg}$ no período desde a concepção até o parto foram relatados por Rocha \& Lobato (2002) em pesquisa com novilhas acasaladas aos 14 meses e recomendaram que as novilhas continuem ganhando peso $(100 \mathrm{~kg})$ no período desde a prenhez ao pós-parto para que voltem a ciclar e repitam prenhez na segunda temporada de monta (Lobato \& Vaz, 2006).

O peso médio dos bezerros ao nascimento foi de $28,3 \mathrm{~kg}$, semelhante aos relatados por Vaz et al. (2010), que verificaram pesos médios de 28,0 kg também trabalhando com novilhas da mesma idade, porém mantidas em melhor estado corporal e maior peso ao parto. Também nesse trabalho os autores observaram uma porcentagem de distocia de 29,8\%, resultado este que não foi observado neste estudo.

A mortalidade média de bezerros ao parto deste experimento foi de $4,6 \%$. Morreu um terneiro das novilhas sob suplementação no nível de $7,0 \mathrm{~g} / \mathrm{kg}$ de peso corporal, que nasceu e morreu asfixiado. Das novilhas sob suplementação no nível de $3,5 \mathrm{~g} / \mathrm{kg}$ de peso corporal morreu um bezerro por mau posicionamento de um membro anterior. Durante a gestação, uma fêmea do grupo sob suplementação com 7,0 g/ $\mathrm{kg}$ de peso corporal abortou dois dias após o manejo de pesagem na mangueira.

\section{Conclusões}

A suplementação energética em campo nativo durante o período reprodutivo melhora linearmente o desenvolvimento e o desempenho reprodutivo de novilhas de corte. Novilhas charolesas são mais pesadas no início e ao fim do período reprodutivo em comparação a novilhas nelores, em função do desenvolvimento prévio, pois os dois genótipos respondem igualmente à suplementação durante o verão, sendo determinante de melhor desempenho reprodutivo.

\section{Referências}

ARIJE, G.F.; WILTBANK, J.N. Age and weight at puberty in Hereford heifers. Journal of Animal Science, v.33, n.2, p.401-406, 1971 .

ASSOCIATION OF OFFICIAL ANALYTICAL CHEMITS - AOAC Official methods of analysis. 14.ed. Washington, D.C.: AOAC Internacional, 1984. 1141p.

BYERLEY, D.J.; STAIGMILLER, R.B.; BERARDINELLI, J.G. et al. Pregnancy rates of beef heifers bred either on puberal or third estrus. Journal of Animal Science, v.65, n.5, p.645-650, 1987.

CERDÓTES, L.; RESTLE, J.; ALVES FILHO, D.C. et al. Desempenho de bezerros de corte filhos de vacas submetidas a diferentes manejos alimentares, desmamados aos 42 ou 63 dias de idade. Revista Brasileira de Zootecnia, v.33, n.3, p.597-609, 2004. 
DEESE, R.E.; KOGER, M. Herdability of reproduction. In: CUNHA, T.J.; WARNICK, A.C.; KOGER, M. (Eds.) Factors affecting calf crop. Gainesville: University of Florida Press, 1967. p.232-238.

FERREL, C.L.; JENKINS, T.G. Cow type and the nutritional environment: nutritional aspects. Journal of Animal Science, v.61, p.725-741, 1985

FREITAS, F.K.; ROCHA, M.G.; RESTLE, J. et al. Suplementação energética na recria de fêmeas de corte em pastagem cultivada de inverno. Produção animal. Revista Brasileira de Zootecnia, v.34, n.4, p.1256-1266, 2005.

FRIES, L.A. Cruzamentos em gado de corte. In: SIMPÓSIO SOBRE PECUÁRIA DE CORTE - Produção do novilho de corte, 1996, Piracicaba. Anais... Piracicaba: FEALQ, 1996. p.109-128.

FRIES, L.A. Critérios de seleção para um sistema de produção de ciclo curto. In: SEMINÁRIO DE AVALIAÇÃO DE BOVINOS DE CORTE E FORMAÇÃO DO CORPO DE JURADOS DA RAÇA ANGUS, 1., 2004, Esteio. Anais... Porto Alegre: ABCA, 2004.p.74-88

FRIZZO, A.; ROCHA, M.G.; RESTLE, J. et al Suplementação energética na recria de bezerras de corte mantidas em pastagem de inverno. Revista Brasileira de Zootecnia, v.32, n.3, p.643-652, 2003

GONÇALVES, E.N.; CARVALHO, P.C.F.; SILVA, C.E.G. et al. Relação planta-animal em ambiente heterogêneo: padrão de desfolhação e seleção de dietas. Revista Brasileira de Zootecnia, v.38, n.4, p.611-617, 2009.

GREGORY, K.E.; CUNDIFF, L.V. Crossbreeding in beef cattle: evaluation of systems. Journal of Animal Science, v.51, n. 5, p. $1224-1241,1980$.

GREGORY, K.E.; LUNSTRA, D.D.; CUNDIFF, L.V. et al. Breed effects and heterosis in advanced generations of compoite populations for puberty and scrotal traits of beef cattle. Journal Animal Science, v.69, n.7 p.2795-2807, 1991.

HALL, J.B.; SCHILLO, K.K.; FITZGERALD, B.P. et al. Effects of recombinant bovine somatropin and dietary energy intake on growth, secretion of luteinizing hormone, follicular development, and onset of puberty in beef heifers. Journal Animal Science, v.72, n.3, p.709-717, 1994.

HAYDOCK, K.P.; SHAW, N.H. The comparative yield method for stimating dry matter yield of pasture. Australian Journal of Experimental Agriculture and Animal Husbandry, v.15, n.76, p.663-670, 1975

LANA, R.P.; GOMES JÚNIOR, P. Sistema de suplementação alimentar para bovinos de corte em pastejo. Validação Revista Brasileira de Zootecnia, v.31, n.1, p.451-459, 2002 (supl.).

LOBATO, J.F.P.; VAZ, R.Z. O manejo do gado de cria no campo nativo. In: SIMPÓSIO DE FORRAGEIRAS E PRODUÇÃO ANIMAL - Ênfase: Importância e potencial produtivo da pastagem nativa, 1., 2006, Porto Alegre. Anais... Porto Alegre: ULBRA, 2006. p.77-114.

LOWMAN, B.G.; SCOTT, N.; SOMERVILLE, S. Condition scoring beef cattle. Edinburgh: East of Scotland College of Agriculture, 1973. 8p.

MORENO, J.A. Clima do Rio Grande do Sul. Porto Alegre. Secretaria da Agricultura. 1961. 41p.

NATIONAL RESEARCH COUNCIL - NRC - Nutrient requeriment of beef cattle. Washington D.C.: National Academy Press, 1996. 244p.

OSORO, K.O. Effecto de las principales variables de manejo sobre los parametros reproductivos en las vacas de cria. Producción y Sanidade Animales, v.1, n.1-2, separata, n.7, p.87-111, 1986.

PASCOAL, L.L; RESTLE, J. Suplementação à campo In: RESTLE,J. (Ed.) Técnicas avançadas na recria e engorda em bovinos de corte. Santa Maria: UFSM, 1996. p.22-34

PEREIRA, L.P.; RESTLE, J.; BRONDANI, I.L. et al. Desenvolvimento ponderal de bovinos de corte de diferentes grupos genéticos de Charolês x Nelore inteiros ou castrados aos 8 meses de idade. Ciência Rural, v.30, n.6, p.1033-1039, 2000.
PEREIRA NETO, O.A.; LOBATO, J.F.P.; SIMEONE, A. Sistema de pastejo rotativo "ponta e rapador" para novilhas de corte 1- Desenvolvimento ponderal. Revista Brasileira de Zootecnia, v.28, n.1, p.137-142, 1999 .

PILAU, A.; ROCHA, M.G.; RESTLE, J. et al. Recria de novilhas de corte com diferentes níveis de suplementação energética em pastagem de aveia preta e azevém. Revista Brasileira de Zootecnia, v.33, n.6, p.2104-2113, 2004 (supl.).

PILAU, A.; LOBATO, J.F.P. Recria de bezerras com suplementação no outono e pastagem cultivada de inverno. Revista Brasileira de Zootecnia, v.35, n.6, p.2388-2396, 2006.

POPPI, D.P.; McLENNAN, S.R. Protein and energy utilization by ruminants at pasture. Journal of Animal Science, v.73, n.1, p.278-290, 1995.

RESTlE, J.; POLli, V.A.; ALVES FILHO, D.C. et al. Desenvolvimento de bovinos de corte de diferentes grupos genéticos desmamados aos 3 ou 7 meses de idade. Revista Brasileira de Zootecnia, v.28, n.5, p.1023-1030, 1999a.

RESTLE, J.; POLLI, V.A.; SENNA, D.B. Efeito de grupo genético e heterose sobre a idade e peso a puberdade e sobre o desempenho reprodutivo de novilhas de corte. Pesquisa Agropecuária Brasileira, v.34, n.4, p.701-707, 1999b.

RESTLE, J.; VAZ, F.N.; ROSO, C. et al. Desempenho e características da carcaça de vacas de diferentes grupos genéticos em pastagem cultivada com suplementação energética. Revista Brasileira de Zootecnia, v.30, n.6, p.1813-1823, 2000

ROCHA, M.G.; LOBATO, J.F.P. Avaliação do desempenho reprodutivo de novilhas de corte primíparas aos dois anos de idade. Revista Brasileira de Zootecnia, v.31, n.3, p.1388-1395, 2002 (supl).

ROVIRA, J.M. Manejo nutritivo de los rodeos de cria em pastoreo. Montevideo: Hemisfério Sur, 1996. 288p.

SEMMELMAN, C.A.N.; LOBATO, J.F.P.; ROCHA, M.G. efeitos de sistemas de alimentação no ganho de peso e desempenho reprodutivo de novilhas Nelore acasaladas aos 17/18 meses. Revista Brasileira de Zootecnia, v.30, n.3, p.835-843, 2001.

SHORT, R.E.; BELLOWS, R.A. Relathionship among weight gains, age at puberty and reproductive performance in heifers. Journal of Animal Science, v.32, n.5, p.1964-1970, 1971.

TIFFIN, J.W. Plane of nutrition and fertility of Mashona heifres mated at $\mathbf{1 5}$ months of age. Division of Livestock and Pasture annual report for the year ended 31 th - September. Salisbury - Rhodesia, 1978. p.34-36.

TILLEY, J.M.A.; TERRY, R.A.A. Two stage technique for the "in vitro" digestion of forage crops. Journal of British Grassland Society, v.18, n.2, p.104-111, 1963.

VAN SOEST, P.J. Nutritional ecology of the ruminant. 2.ed. Cornel University: Cornel University Press, 1994. 476p.

VAZ, F.N.; ROSO, C.; VAZ, R.Z. Aplicação gerenciamento de tecnologias na pecuária de corte moderna In: RESTLE, J. (Ed.) Eficiência na produção de bovinos de corte. Santa Maria: UFSM, 2000. p.333-368.

VAZ, R.Z.; LOBATO, J.F.P. Efeito da idade de desmame no desempenho reprodutivo de novilhas de corte expostas à reprodução aos 13/15 meses de idade. Revista Brasileira de Zootecnia, v.39, n.1, p.142-150, 2010a.

VAZ, R.Z.; LOBATO, J.F.P. Efeito da idade de desmame no desenvolvimento de novilhas de corte até os 14/15 meses de idade. Revista Brasileira de Zootecnia, v.39, n.2, p.289-298, 2010 b.

VAZ, R.Z.; LOBATO, J.F.P.; RESTLE, J. Influence of weaning age on the reproductive efficiency of primiparous cows. Revista Brasileira de Zootecnia, v.39, n.2, p.299-307, 2010.

WILTBANK, J.N.; ROBERTS, J.N.; ROWDEN, L. Reproductive performance and profitability of heifers feed to weight 272 or $318 \mathrm{~kg}$ at the start of the first breeding season. Journal of Animal Science, v.60, n.1, p.25-35, 1985. 